\title{
Effect of Opuntia ficus-indica Mucilage Edible Coating in Combination with Ascorbic Acid, on Strawberry Fruit Quality during Cold Storage
}

\author{
Giorgia Liguori (D), Raimondo Gaglio $(\mathbb{D}$, Luca Settanni $(\mathbb{D}$, Paolo Inglese $(\mathbb{D}$, \\ Fabio D'Anna $\mathbb{1}$, and Alessandro Miceli $(\mathbb{C})$ \\ Department of Agricultural Food and Forest Sciences, University of Palermo, Viale Delle Scienze, Palermo 90128, Italy \\ Correspondence should be addressed to Giorgia Liguori; giorgia.liguori@unipa.it
}

Received 5 March 2021; Revised 13 May 2021; Accepted 18 May 2021; Published 30 May 2021

Academic Editor: Francesco Genovese

Copyright $\odot 2021$ Giorgia Liguori et al. This is an open access article distributed under the Creative Commons Attribution License, which permits unrestricted use, distribution, and reproduction in any medium, provided the original work is properly cited.

\begin{abstract}
Strawberry fruit is a nonclimacteric fruit and is one of the most consumed berries in the world. It is characterized by high levels of vitamin $\mathrm{C}$, folate, vitamin $\mathrm{E}, \beta$-carotene, and phenolic constituents as well asanthocyanins that are strictly related to health benefits. Strawberries are highly perishable fruit with a very short postharvest life due to their susceptibility to mechanical injury, rapid texture softening, physiological disorders, and infection caused by several pathogens (yeast and mold) that can rapidly reduce fruit quality. The aim of the present study was to evaluate the effect of the application of Opuntia ficus-indica mucilage in combination with ascorbic acid, as edible coating, on quality, sensorial parameters, and microbiological characteristics of strawberry fruit during cold storage at $4 \pm 0.5^{\circ} \mathrm{C}$ and $85 \% \mathrm{RH}$. Strawberries were characterized by a linear increase of weight loss during the storage at $4^{\circ} \mathrm{C}$ that was significantly higher $(+11.3 \%$ on average) in the uncoated strawberries. The coating affected the ascorbic acid content of the strawberries that increased by $36.0 \%$ in coated strawberries; total soluble solid content and color of the strawberries were only affected by storage. Visual quality and sensorial analysis recorded higher scores in the coated samples at the end of the cold storage period. Furthermore, the mucilage coating did not negatively affect the natural taste of strawberries. The application of O. ficus-indica gel-based edible coating in combination with ascorbic acid, although not able to inhibit the microbial growth, limited significantly their development in coated strawberry fruits. Our results suggest that Opuntia mucilage plus 5\% ascorbic acid could be a useful biochemical way of maintaining strawberry fruit quality and extending their postharvest life.
\end{abstract}

\section{Introduction}

Strawberry fruit (Fragaria $\times$ ananassa Duch.) is a nonclimacteric fruit and is one of the most consumed berries in the world, characterized by a peculiar and highly appreciated taste and flavor. Strawberry is a relevant source of bioactive compounds because of its high levels of vitamin C, folate, vitamin $\mathrm{E}, \beta$-carotene, and phenolic constituents, as well as anthocyanins, substances strictly related to health benefits $[1,2]$. Strawberries are highly perishable fruit with a very short postharvest life due to their susceptibility to mechanical injury, rapid texture softening, physiological disorders, and infection caused by several pathogens (yeast and mold) that can rapidly reduce fruit quality $[1,3]$.
Several technologies have been developed for strawberry preservation during postharvest, such as controlled atmospheres, hot water treatments, UV, and chemical treatments, but most of them have negative effects on color, flavor, aroma, and texture $[1,4]$. In the past, fungicides were used to control mold and yeast growth, but several studies confirm that they can leave residues that could be dangerous for human health and the environment [5]. For this reason, consumers prefer natural and eco-friendly fruit products without any chemical additives [1]. A common technology used to control mold growth and reduce fruit senescence is cold storage under controlled/modified conditions, but high $\mathrm{CO}_{2}$ concentrations can cause off-flavor development on fruit [6]. 
Among different postharvest management strategies of environment-friendly fresh fruit handling, the application of edible coatings has been reported to be very effective [7].

Edible coatings can act as a semipermeable barrier against gases and water vapor. It can modify fruit tissue metabolism by affecting respiration rate, decreasing moisture and firmness loss, preserving the color, transporting antimicrobial, antioxidant, and other preservatives, controlling microbial growth and maintaining fruit quality for a longer period $[6,8]$. Several studies reported that the applications of edible coatings improved quality, extended storage, and shelf life of various fruit such as papaya [9], kiwifruit [10], and strawberries [11].

A novel edible coating for fruit storage based on the mucilage or polysaccharides extracted from cladodes of Opuntia ficus-indica was recently investigated on kiwifruit slices [10], breba fig [12], strawberry [13], banana [14], tomato [15], and mandarin [16].

Those studies reported that $O$. ficus-indica edible coating positively affected fruit quality, reducing water transpiration and browning, maintaining fruit fresh weight, visual score values, fruit firmness, nutraceutical traits, and controlling microbial growth, resulting in a longer storage period $[10,12-16]$.

O. ficus-indica mucilage is a complex carbohydrate composed of variable amounts of l-arabinose, d-galactose, 1-rhamnose, and d-xylose, as well as galacturonic acid, which is a potential ingredient for the food industry, due to its nutritional and technological properties, such as viscosity [17]. Mucilage is, in fact, a hydrocolloid with a great water retention capacity that makes it interesting for the production of natural edible coatings with a high nutraceutical value, useful for fruit and food preservation [18].

Another compound widely used in fruit products during storage is ascorbic acid (AA) in concentrations ranging from 0.5 to $5 \% \mathrm{w} / \mathrm{v}[11]$. Several authors reported that AA has an antibrowning effect in fruit fresh-cut products under different storage conditions $[9,19]$ and reduces vitamin $C$ degradation during storage [11]. Other studies reported that AA has an antimicrobial effect on fresh-cut fruit such as jackfruit [20], apple [21], and papaya [9] and it can be added to the edible coating to improve the shelf-life of the fruit.

Sogvar et al. [11] reported that the application of Aloe vera in combination with AA on strawberry fruit improves the postharvest life by maintaining fruit quality attributes as well as firmness, solid soluble content, titratable acidity, vitamin $\mathrm{C}$, anthocyanin, total phenolic, and total antioxidant activity and reduces decay by suppression of total aerobic mesophilic bacteria, yeasts, and mold growth. Other studies showed that coating with chitosan and ascorbic acid is an effective solution for inhibiting the growth of microorganisms, retarding enzymatic browning reactions, and reducing the weight loss of fresh-cut apples during refrigerated storage [22].

Those studies suggest that the addition of AA to the edible coating could be a useful biochemical way of maintaining strawberry fruit quality and extending their postharvest life. However, further studies are necessary to study how the addition of AA to different edible coatings, such as O. ficus-indica mucilage, could affect microbial growth and physicochemical traits of strawberry fruits during cold storage. The aim of the present study was to evaluate the effect of the application of O. ficus-indica mucilage in combination with ascorbic acid, as edible coating, on quality, sensorial parameters, and microbial growth of strawberry fruits during cold storage at $4 \pm 0.5^{\circ} \mathrm{C}$ and $85 \% \mathrm{RH}$.

\section{Materials and Methods}

2.1. Strawberry Fruits. The strawberry fruits (cv. Florida Fortuna) used in the trial were collected in the experimental farm of the Department of Agricultural, Food and Forest Science (SAAF), University of Palermo, located in Marsala $\left(37^{\circ} 45^{\prime} 02.8^{\prime \prime} \mathrm{N} 12^{\circ} 32^{\prime} 32.10^{\prime \prime} \mathrm{E}, 50 \mathrm{~m}\right.$ a.s.l.) and immediately transported to the research laboratory of the SAAF Department, University of Palermo, where they were graded for their uniformity in size, shape, and bright red color. A bulk of homogeneous fruits free from defects was selected for the coating treatment and subsequent cold storage. The selected fruits were divided into two treatment groups of 20 replicates ( 4 replicates for each of 5 storage sampling times).

2.2. Fresh Mucilage Extraction. One-year-old cladodes were collected from O. ficus-indica (OFI) plants grown in the germplasm collection of the SAAF Department of the University of Palermo ( $38^{\circ} 7^{\prime} \mathrm{N} 13^{\circ} 2^{\prime} \mathrm{E}, 29 \mathrm{~m}$ a.s.l). Harvested cladodes were moved to the laboratory, where they were processed for mucilage extraction, using a modified version of Du Toit and De Wit's patented method, developed in South Africa [23].

Cladodes were washed with chlorinated water to improve mucilage shelf life and to remove impurities and spines. Cladode chlorenchyma was removed with a peeler to obtain very pure mucilage from the parenchyma. Cladodes were then sliced into squares and cooked in a microwave oven $(900 \mathrm{~W})$ for $3-5 \mathrm{~min}$, until soft. The cooked, soft cladode pieces were then mixed using an Omni Mixer Homogenizer (mod. Omni-Mixer, 17107, Dupont Instruments Sorvall, Kennesaw GA, USA) to aid the mucilage extraction. The obtained pulp was then centrifuged using a Sigma centrifuge (mod. 6K15, Sigma Laborzentrifugen $\mathrm{GmbH}$, Osterode am Harz, Germany) at $8,117 x \mathrm{~g}$ for $15 \mathrm{~min}$ at $4^{\circ} \mathrm{C}$, to separate the liquid mucilage from the solids. The mucilage was then decanted and weighed while the solid material left in the falcon tubes was discarded. No chemicals have been used during this extraction process.

2.3. Fresh Mucilage Edible Coating Application. Half of the selected strawberries were treated with OFI mucilage in combination with $5 \%$ of ascorbic acid [11] and the remaining strawberries were treated with distilled water and used as control. Mucilage edible coating and distilled water were applied by using an atomizing spray system (flow rate: $1 \mathrm{~L} \cdot \mathrm{h}^{-1}$; air pressure: $50 \mathrm{kPa}$ ). Soon after coating, all fruits were air-dried at room temperature for 
15 , then placed in polyethylene (PE) boxes (each a 10 fruit replicate), and stored at $4 \pm 0.5^{\circ} \mathrm{C}$ and $85 \% \mathrm{RH}$ for 12 days.

2.4. Quality Parameters: Weight Loss, Color, Overall Quality, Firmness, Soluble Solid Content, Titratable Acidity, and Ascorbic Acid Content. The quality of strawberries was assessed soon after coating $(0 \mathrm{~d})$ and at 3, 6, 9, and $12 \mathrm{~d}$ of storage at $4^{\circ} \mathrm{C}$. For each storage time and experimental treatment, four samples of five strawberries were randomly collected and analyzed. The fruits were weighed at each sampling time to evaluate weight loss. Strawberries' external color was measured at two opposite points on each strawberry using a colorimeter (Chroma Meter CR-400C, Minolta, Osaka, Japan). CIE $L^{*} a^{*} b^{*}$ coordinates were recorded as $L^{*}$ (lightness), $a^{*}$ (positive values for reddish colors and negative values for greenish colors), and $b^{*}$ (positive values for yellowish colors and negative values for bluish colors). From these components, chroma $\left(C^{*}\right)$ and hue angle $\left(h^{\circ}\right)$ were calculated as $C^{*}=\left(a^{* 2}+b^{* 2}\right)^{1 / 2}$ and $h^{\circ}=\arctan \left(b^{*} / a^{*}\right)$ [24]. Overall visual quality (OQ) was evaluated by a panel made of 10 people ( 5 females and 5 males, aged between 25 and 50 years) using a 1 to 5 scale, where $5=$ excellent product with a fresh appearance and optimal sensory acceptability (e.g., typical odor and color, no defects), $3=$ fair/limit of sensory acceptability and marketability (e.g., minor alterations), and $1=$ poor/unmarketable, with altered odor, extended discolored or decayed area, or other severe defects.

Fruit firmness was measured using a digital penetrometer (model 53205, TR Snc., Forlì, Italy) equipped with flat stainless steel cylinder probes of $6 \mathrm{~mm}$ diameter. Each fruit was punched with constant force to a depth of $0.5 \mathrm{~cm}$ and the mean peak force was calculated in Newton. After firmness analysis, the fruits of each sample were cut into small pieces and homogenized. Ten grams of the homogenate was suspended in $100 \mathrm{~mL}$ of distilled water and then filtered. The extracts were used to determine the soluble solid content (SSC expressed as ${ }^{\circ}$ Brix) using a digital refractometer (MTD045nD, Three-In-One Enterprises Co., Ltd., Taipei, Taiwan) and to measure the titratable acidity (TA) by potentiometric titration with $0.1 \mathrm{M} \mathrm{NaOH}$ up to $\mathrm{pH}$ 8.1 (TA expressed as meq $100 \mathrm{~g}^{-1}$ fresh weight [f.w.]). Ascorbic acid content was determined by extracting $10 \mathrm{~g}$ of a blended strawberry sample from each sampling date $(0,3,6,9$, and 12 days of storage) in $100 \mathrm{~mL}$ metaphosphoric acid $\left(\mathrm{HPO}_{3}\right)$ and then filtered through Whatman no. 1 filter paper. A volume of $10 \mathrm{~mL}$ from the filtered solution was determined volumetrically with the 2-6 dichlorophenol-indophenol reagent until a slightly pink coloration was observed and persisted for $15 \mathrm{~s}$ [25]. The reading of ascorbic acid content was expressed in $\mathrm{mg} 100 \mathrm{~g}^{-1}$ fruit sample.

2.5. Sensory Analysis. For each sampling date, a sample of fruit for each treatment was subjected to sensory evaluation. The sensory profile was constructed by a semitrained panel made of 10 judges ( 5 females and 5 males, aged between 25 and 50 years) who generated a list of descriptors by using commercial fruit in a few preliminary meetings [26]. The semitrained panel was made up of people normally familiar with strawberries. This type of panel can discriminate differences and communicate their reactions, though the individuals may not have been formally trained; furthermore, a semitrained panelist judgment is likely to be closer to that of the average consumer [27]. Sensory analysis was focused on 6 principal descriptors: firmness, sweetness, acidity, aroma, taste, and off-flavor [28].

Strawberries sample was dispensed into a small plastic tray with a 3-digit code on the side and served to the judges, and the different descriptors were measured using an eightpoint intensity scale where the digit 1 indicates the descriptor absence while the digit 8 indicates the full intensity. Among the judges, the order of presentation of the fruit was randomized; water was used to rinse the mouth [27].

2.6. Microbiological Analyses. O. ficus-indica mucilage added with ascorbic acid and the fruit samples from the different trials and storage times were subjected to the microbiological analyses. Cell suspensions of mucilage were directly subjected to decimal serial dilutions in Ringer's solution (Sigma-Aldrich, Milan, Italy), while fruit samples were first homogenized in Ringer's solution (Sigma-Aldrich) to a ratio $1: 10$ (fruit: diluent) by the Bag-Mixer 400 stomacher (Interscience, Saint Nom, France) for 2 min at the highest speed (blending power 4) and then serially diluted in the same isotonic solution.

Decimal dilutions were plated on several agar media: Plate Count Agar (PCA), incubated aerobically for $72 \mathrm{~h}$ at $30^{\circ} \mathrm{C}$ for total mesophilic microorganisms (TMM); PCA incubated aerobically for $7 \mathrm{~d}$ at $7^{\circ} \mathrm{C}$ for total psychrotrophic microorganisms (TPM); Pseudomonas Agar Base (PAB) added with Cetrimide Fucidin Cephaloridine (CFC) supplement, incubated aerobically for $48 \mathrm{~h}$ at $25^{\circ} \mathrm{C}$ for pseudomonads; double-layered Violet Red Bile Glucose Agar (VRBGA), incubated at $37^{\circ} \mathrm{C}$ for $24 \mathrm{~h}$ for members of the Enterobacteriaceae family; Dichloran Rose Bengal Chloramphenicol (DRBC) agar, incubated aerobically for $48 \mathrm{~h}$ at $28^{\circ} \mathrm{C}$ for yeasts; Yeast extract Peptone Dextrose (YPD) agar supplemented with $0.1 \mathrm{~g} \cdot \mathrm{L}^{-1}$ of chloramphenicol to avoid bacterial growth, incubated aerobically for $7 \mathrm{~d}$ at $25^{\circ} \mathrm{C}$ for molds.

All media and supplements were purchased from Biotec (Grosseto, Italy). All plate counts were carried out in triplicate.

2.7. Statistical Analysis. Statistical analyses of quality and sensory parameters were performed using the GLM procedure of the SPSS 14.0 software package (SPSS, Inc., Chicago, IL) and the means were compared by Tukey's test at a significance level of 0.05 .

Microbiological data were subjected to One-Way Variance Analysis (ANOVA) using XLStat software version 2020.3.1 for Excel (Addinsoft, New York, USA). The level of significance and the differences between control and experimental trials were achieved by Tukey's test. $P<0.05$ was considered significant. 


\section{Results and Discussion}

3.1. Quality Parameters: Weight Loss, Color, Overall Quality, Firmness, Soluble Solid Content, Titratable Acidity, and Ascorbic Acid Content. Strawberries were characterized by a linear increase of weight loss during the storage at $4^{\circ} \mathrm{C}$ (Table 1$)$. A higher weight loss $(+11.3 \%$ on average) was recorded in the uncoated strawberries. The effect of OFI mucilage coating on weight loss was similar to other edible coatings tested on strawberry fruits [29] and a reduction of weight was also found in sliced or entire fruits (kiwi, fig, strawberry) coated with cactus mucilage $[10,12,13,30]$ and could be ascribed to the increased retention of water due to the reduction of transpiration and respiration determined by the hydrophilic character of mucilage coating that closed the opening of stomata and lenticels [31]. After harvest, the weight of the fruits is likely to change due to several factors, including loss of extracellular and intracellular water, sugar consumption determined by cellular respiration and degradation of the cell wall, and consequent loss of water by the cell breakdown [32]. These factors and loss in cell turgidity pressure and loss of extracellular and vascular air may also lead to the modification of tissue texture. Measuring the mechanical properties of fruits like strawberries can be challenging, as their structure is very inhomogeneous. They vary a lot in shape and size, so it can be very difficult to take a uniform sample from tested strawberries. Puncture testing has often been used to measure and follow changes in texture and firmness of fruits and vegetables at different preharvest and postharvest stages. The use of the puncture penetration method allows evaluating both the skin toughness and the flesh firmness of strawberries [33]. The firmness of strawberries was affected by storage that determined a significant reduction of this parameter after 6 days at $4^{\circ} \mathrm{C}$ for control fruit, with further significant changes recorded after 9 days and at the end of the storage period so that strawberry decreased from $10.4 \mathrm{~N}$ at day 0 to $7.3 \mathrm{~N}$ at day 12 for both coated and uncoated samples (Table 1). Nevertheless, the coated strawberries retained a slightly higher firmness after 6 and 9 days of storage at $4^{\circ} \mathrm{C}$, so that this treatment determined a higher firmness than control $(+5.1 \%$ on average). The decrease in fruit firmness during cold storage might be due to the breakdown of cell wall components such as insoluble pectin and also due to cellular collapse [34] that could have been reduced in the coated fruits. A lower decrease of firmness during cold storage was also found in strawberries and other fruits coated with OFI mucilage $[10,12,13]$. This could be ascribed to the presence of calcium in OFI mucilage [35] that interacts with the pectic acid in the cell walls to form calcium pectate, thus retaining the integrity of cell walls in fruit tissues.

Storage also affected the soluble solid content of the strawberries (Table 1). This parameter was almost constant during the first week of storage $\left(7.5^{\circ}\right.$ Brix on average $)$ and significantly increased at the end of the experiment (8.6 ${ }^{\circ}$ Brix). A similar trend was recorded for the titratable acidity (TA) that increased significantly at the end of the storage period $(+26.1 \%)$ (Table 1$)$. The increase in soluble solid content might be due to hydrolysis into sugars and to the capacity of cold storage to slow down the metabolic activities of strawberries during storage [29]. The effect of cold storage in combination with the edible coating application on metabolic activities could have also reduced the utilization of organic acid during the respiratory process thus explaining their increase during cold storage, as reported by Hazarika et al. [29].

The coating affected the ascorbic acid content of the strawberries that increased by $36.0 \%$ in coated strawberries (Table 1). This parameter showed small variations during storage that were significant only at day 3 . Ascorbic acid is an important phytochemical with powerful antioxidant activity and can scavenge the reactive oxygen species (ROS) produced in the body thus protecting from many severe diseases [36]. The cactus mucilage coating showed to be useful in increasing the nutritional value of strawberries during the entire storage period.

The color of the strawberries was only affected by storage (Table 1). Color lightness decreased from 41.5 at day 0 to 37.6 at day 3 and showed no further reduction until the end of the experiment. Chroma and hue decreased more severely during storage so that the color of strawberries got less vivid and turned to the darkest red. Visual quality is of paramount importance in affecting strawberry acceptance and marketability. Appearance changes that strawberries may suffer during storage can be symptoms of freshness loss and microbiological decay [37]. The overall appearance of coated and uncoated strawberries changed significantly during storage, but control strawberries had a more severe descending trend of the OQ scores that dropped below the limit of marketability after seven days of storage, whereas the strawberries coated with cactus mucilage recorded OQ scores above the limit of marketability throughout the storage period (12 days) (Figure 1).

3.2. Microbiological Counts. Strawberry is a highly perishable fruit and its shelf-life is usually influenced by different microbial infections determined by bacteria, yeasts, and molds [38]. Table 2 shows the results of the microbiological analyses of the strawberry fruit samples collected during the experimentation. The results of viable counts performed on O. ficus-indica mucilage are not reported in the table because they were below the detection limit for all microbial groups objects of investigation. Statistically significant differences were found according to Tukey's test for the levels of TMM, TPM, and molds between coated and uncoated strawberry fruits. The initial concentrations of TMM, TPM, and molds in control fruits (C) were 3.04, 2.81, and 3.34 $\mathrm{Log}_{\mathrm{CFU} \mathrm{g}}{ }^{-1}$, respectively, and increased during refrigerated storage. Even in coated strawberry fruits (MA), these microbial populations increased during storage but showed lower microbial cell densities than the untreated fruits. The same trend was reported by Sogvar et al. [11] on strawberry fruits treated with Aloe vera gel-based edible coating in combination with ascorbic acid. No colonies of pseudomonads and yeasts responsible for the microbial spoilage of fruits and vegetables [39] were detected in any of the samples analyzed. Members of the 
TABLE 1: Chemical and physical parameters of strawberries coated with cactus mucilage + ascorbic acid (MA) or uncoated (C) during storage at $4^{\circ} \mathrm{C}$.

\begin{tabular}{|c|c|c|c|c|c|c|c|c|c|}
\hline \multicolumn{2}{|c|}{$\begin{array}{l}\text { Source of } \\
\text { variance }\end{array}$} & 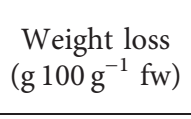 & $\begin{array}{l}\text { Firmness } \\
(\mathrm{N})\end{array}$ & $\begin{array}{l}\text { SSC } \\
\left({ }^{\circ} \text { Brix }\right)\end{array}$ & $\begin{array}{c}\text { TA } \\
\text { (meq } 100 \mathrm{~g}^{-1} \text { fw.) }\end{array}$ & 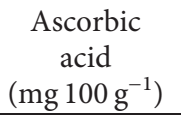 & $L^{*}$ & Chroma & Hue \\
\hline \multicolumn{10}{|c|}{ Coating } \\
\hline $\mathrm{C}$ & & $9.0 \mathrm{~b}$ & $9.2 \mathrm{~b}$ & 7.7 & 10.6 & $36.9 \mathrm{~B}$ & 37.5 & 46.5 & 37.7 \\
\hline MA & & $8.1 \mathrm{a}$ & $9.7 \mathrm{a}$ & 7.9 & 11.0 & $50.2 \mathrm{~A}$ & 38.0 & 46.6 & 38.3 \\
\hline \multicolumn{10}{|c|}{ Storage } \\
\hline 0 & & - & $10.2 \mathrm{~d}$ & $7.4 c$ & $10.1 \mathrm{~b}$ & $44.6 \mathrm{~A}$ & $41.5 \mathrm{~A}$ & $48.8 \mathrm{~A}$ & $42.1 \mathrm{a}$ \\
\hline 3 & & $3.6 \mathrm{~d}$ & $10.6 \mathrm{bc}$ & $7.5 \mathrm{c}$ & $10.5 \mathrm{ab}$ & $37.7 \mathrm{~B}$ & $37.6 \mathrm{~B}$ & $47.0 \mathrm{~B}$ & $38.4 \mathrm{~b}$ \\
\hline 6 & & $6.8 c$ & $9.9 c$ & $7.7 c$ & $11.3 \mathrm{a}$ & $43.9 \mathrm{~A}$ & $36.7 \mathrm{~B}$ & $45.5 \mathrm{Bc}$ & $37.1 \mathrm{bc}$ \\
\hline 9 & & $9.8 \mathrm{~b}$ & $9.2 \mathrm{a}$ & $8.0 \mathrm{bc}$ & $11.2 \mathrm{a}$ & $44.0 \mathrm{~A}$ & $36.1 \mathrm{~B}$ & $46.0 \mathrm{Bc}$ & $36.9 \mathrm{bc}$ \\
\hline 12 & & $13.9 \mathrm{a}$ & $7.3 \mathrm{ab}$ & $8.6 \mathrm{a}$ & $11.0 \mathrm{a}$ & $47.7 \mathrm{~A}$ & $36.8 \mathrm{~B}$ & $45.2 \mathrm{C}$ & $35.3 c$ \\
\hline \multicolumn{10}{|c|}{ Coating x Storage } \\
\hline \multirow{5}{*}{ C } & 0 & - & 10.2 & 7.4 & 10.1 & 40.1 & 41.5 & 48.8 & 42.1 \\
\hline & 3 & 3.9 & 10.6 & 7.5 & 9.9 & 30.7 & 37.5 & 46.9 & 37.2 \\
\hline & 6 & 7.2 & 9.4 & 7.8 & 10.7 & 38.5 & 36.2 & 45.0 & 36.5 \\
\hline & 9 & 10.3 & 8.7 & 7.7 & 11.4 & 35.6 & 35.1 & 46.4 & 36.0 \\
\hline & 12 & 14.5 & 7.2 & 8.3 & 11.0 & 39.8 & 37.2 & 45.1 & 36.5 \\
\hline \multirow{5}{*}{ MA } & 0 & - & 10.2 & 7.4 & 10.1 & 49.0 & 41.5 & 48.8 & 42.1 \\
\hline & 3 & 3.3 & 10.6 & 7.5 & 11.0 & 44.7 & 37.8 & 47.2 & 39.6 \\
\hline & 6 & 6.4 & 10.4 & 7.7 & 11.8 & 49.3 & 37.2 & 46.0 & 37.8 \\
\hline & 9 & 9.3 & 9.7 & 8.3 & 11.0 & 52.5 & 37.1 & 45.6 & 37.9 \\
\hline & 12 & 13.2 & 7.5 & 8.9 & 11.1 & 55.7 & 36.3 & 45.4 & 34.2 \\
\hline \multicolumn{10}{|c|}{ Significance ${ }^{x}$} \\
\hline Coat & & $*$ & $*$ & ns & ns & $* * *$ & ns & ns & ns \\
\hline Stora & & $* * *$ & $* * *$ & $* * *$ & $*$ & $* * *$ & $* * *$ & $* * *$ & $* * *$ \\
\hline $\begin{array}{l}\text { Coat } \\
\text { Stora }\end{array}$ & & ns & $\mathrm{ns}$ & $\mathrm{ns}$ & ns & ns & ns & $\mathrm{ns}$ & ns \\
\hline
\end{tabular}

Each value is the mean of 4 replicated samples. Values in a column followed by different letters are significantly different according to Tukey's test at $p \leq 0.05$. ${ }^{x}$ Significance: $\mathrm{ns}=$ not significant; ${ }^{*}$ significant at $p<0.05 ;{ }^{* *}$ significant at $p<0.01 ;{ }^{* * *}$ significant at $p<0.001 .{ }^{y}$ Titratable acidity expressed as meq $/ 100 \mathrm{~g}$ fresh weight.

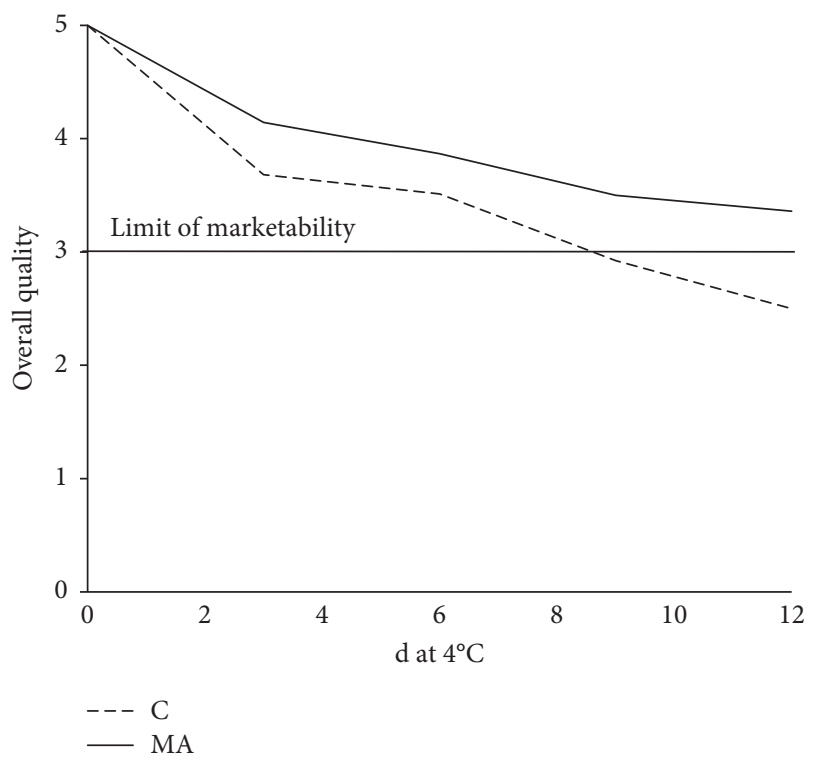

FIGURE 1: Influence of coating and time of storage on the overall visual quality of strawberry fruits (C: control fruits; MA: fruits coated with cactus mucilage + ascorbic acid; scores: 5 , excellent or having a fresh appearance; 3 , average limit of marketability; 1 , unmarketable).
Enterobacteriaceae family, responsible for gastroenteritis and even chronic infections [40, 41], were below the detection limit in both coated and control strawberry fruits during the entire period of analysis.

3.3. Sensory Analysis. Uncoated (C) and coated (MA) strawberry fruit samples were subjected to sensory evaluation on each sampling date. Strawberry fruits were positively affected by mucilage coating in combination with the ascorbic acid treatment; indeed panelists preferred MA samples in each sampling date (data not shown).

MA samples showed mean scores 0.5 higher in terms of sensory evaluation than $\mathrm{C}$ samples after 3 days of storage at $4^{\circ} \mathrm{C}$ (Figure 2). In particular, judges perceived the largest difference in the aroma descriptor in MA samples with scores 1.6 higher than $\mathrm{C}$ ones (Figure 2).

At the end of the storage (12 days), MA samples were preferred by judges showing the highest scores in all sensorial parameters, and MA samples obtained sensory evaluation mean scores 1.2 higher than $\mathrm{C}$ ones (Figure 3). Panelists perceived off-flavor in $\mathrm{C}$ samples after 9 (data not shown) and 12 days at $4^{\circ} \mathrm{C}$ (Figure 3 ), while the perception of 
TABLE 2: Microbial loads of control (C) and coated (O. ficus-indica mucilage in combination with ascorbic acid-MA) strawberry fruit samples during storage at $4^{\circ} \mathrm{C}$.

\begin{tabular}{lccc}
\hline Samples & \multicolumn{3}{c}{ Microorganisms } \\
& TMM & TPM & Molds \\
\hline C 0 d & $3.04 \pm 0.22^{\mathrm{a}}$ & $2.81 \pm 0.15^{\mathrm{a}}$ & $3.34 \pm 0.23^{\mathrm{a}}$ \\
MA 0 d & $2.99 \pm 0.19^{\mathrm{a}}$ & $2.88 \pm 0.23^{\mathrm{a}}$ & $3.26 \pm 0.12^{\mathrm{a}}$ \\
C 3 d & $3.19 \pm 0.17^{\mathrm{a}}$ & $3.30 \pm 0.27^{\mathrm{a}}$ & $3.49 \pm 0.21^{\mathrm{a}}$ \\
MA 3d & $2.74 \pm 0.12^{\mathrm{b}}$ & $2.72 \pm 0.11^{\mathrm{b}}$ & $2.89 \pm 0.15^{\mathrm{b}}$ \\
C 6 d & $3.59 \pm 0.21^{\mathrm{a}}$ & $3.47 \pm 0.25^{\mathrm{a}}$ & $3.65 \pm 0.26^{\mathrm{a}}$ \\
MA 6d & $3.01 \pm 0.15^{\mathrm{b}}$ & $2.95 \pm 0.20^{\mathrm{b}}$ & $2.96 \pm 0.17^{\mathrm{b}}$ \\
C 9 d & $3.75 \pm 0.18^{\mathrm{a}}$ & $3.70 \pm 0.24^{\mathrm{a}}$ & $3.81 \pm 0.19^{\mathrm{a}}$ \\
MA 9d & $3.15 \pm 0.21^{\mathrm{b}}$ & $3.07 \pm 0.22^{\mathrm{b}}$ & $3.10 \pm 0.24^{\mathrm{b}}$ \\
C 12 d & $4.08 \pm 0.24^{\mathrm{a}}$ & $4.12 \pm 0.21^{\mathrm{a}}$ & $4.23 \pm 0.21^{\mathrm{a}}$ \\
MA 12 d & $3.49 \pm 0.19^{\mathrm{b}}$ & $3.38 \pm 0.19^{\mathrm{b}}$ & $3.59 \pm 0.25^{\mathrm{b}}$ \\
\hline
\end{tabular}

Units are $\log \mathrm{CFU} \mathrm{g}^{-1}$. Results indicate mean values \pm S.D. of three plate counts. Data within a column followed by the same letter between the $\mathrm{C}$ and MA on the same day of refrigerated storage are not significantly different according to Tukey's test at $p<0.05$.

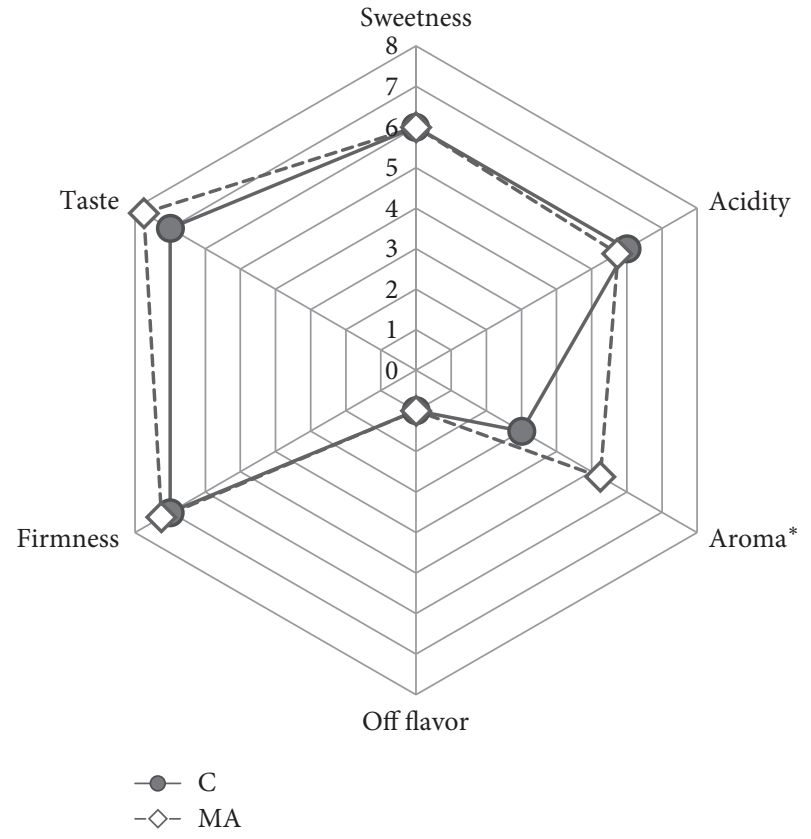

Figure 2: Sensory analysis of untreated (C) and treated (O. ficusindica mucilage in combination with ascorbic acid-MA) strawberry "Fortuna" fruit, after 3 days of storage at $4^{\circ} \mathrm{C}$. Data are mean of 15 fruit for each treatment. * Significant differences for values (Tukey's test at $p<0.05)$.

this descriptor was almost absent in MA samples in each sampling date (Figures 2 and 3).

The sensory analysis showed that judges had a higher preference for coated samples at the end of the cold storage period, as reported by Del-Valle et al. [13]. The mucilage

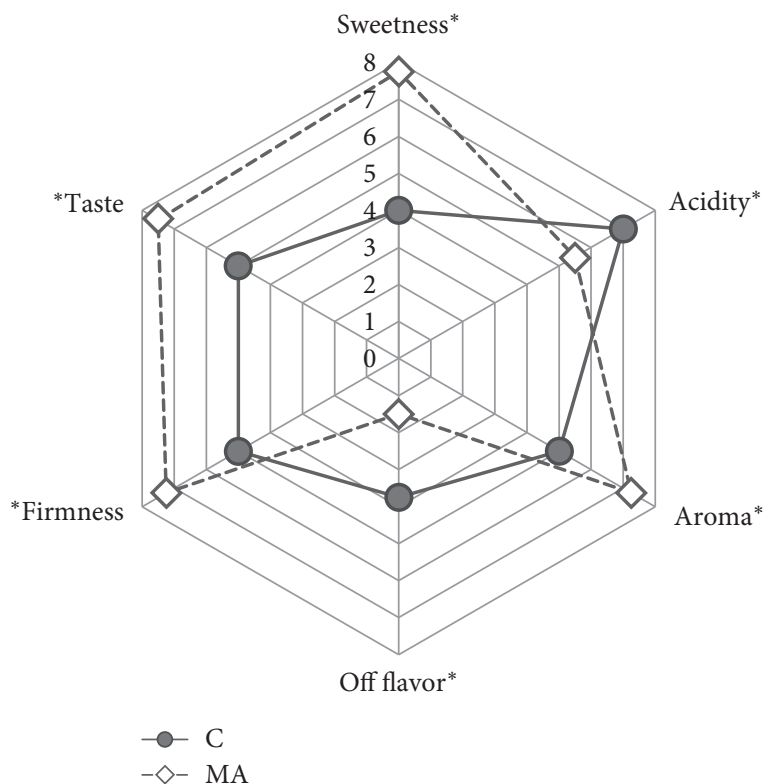

Figure 3: Sensory analysis of untreated (C) and treated (O. ficusindica mucilage in combination with ascorbic acid-MA) strawberry "Fortuna" fruit, after 12 days of storage at $4^{\circ} \mathrm{C}$. Data are Mean of 15 fruit for each treatment. *Significant differences for values (Tukey's test at $p \leq 0.05)$.

coating did not negatively affect the natural taste of strawberries, which is an important aspect regarding the use of edible coatings when taste modification is undesirable. Indeed, MA coating has exalted some important parameters, as well as aroma, sweetness, and taste that are particularly appreciated by consumers.

\section{Conclusions}

Our data showed that Opuntia mucilage had a barrier effect on strawberries after harvest, reflected by the lower weight loss and a slightly higher firmness of coated samples than uncoated ones, after 9 days of storage at $4^{\circ} \mathrm{C}$. This factor could reduce economic losses due to spoilage caused by mechanical damage during the handling and transportation of strawberries. The addition of ascorbic acid in the cactus mucilage coating showed to be useful in increasing the nutritional value of strawberries during the entire storage period. Soluble solid content and color were affected only by storage and not by the coating treatment.

Visual quality and sensorial analysis showed that judges had a higher preference for coated samples at the end of the cold storage period. Furthermore, the mucilage coating did not affect negatively the natural taste of strawberries, which is an important aspect regarding the use of edible coatings 
when taste modification is undesirable. Indeed, MA coating has exalted some important parameters and aroma, sweetness, and taste that are particularly appreciated by consumers.

From the microbiological point of view, the application of O. ficus-indica gel-based edible coating in combination with ascorbic acid is not able to inhibit the microbial growth but slowed down significantly their development in coated strawberry fruits.

In conclusion, our data suggest that $O$. ficus-indica mucilage plus $5 \%$ of ascorbic acid could be a useful biochemical way of maintaining strawberry fruit quality and extending its postharvest life.

\section{Data Availability}

The data are available from the corresponding author upon request.

\section{Conflicts of Interest}

The authors declare that they have no conflicts of interest.

\section{References}

[1] N. B. Gol, P. R. Patel, and T. V. R. Rao, "Improvement of quality and shelf-life of strawberries with edible coatings enriched with chitosan," Postharvest Biology and Technology, vol. 85, pp. 185-195, 2013.

[2] F. Giampieri, S. Tulipani, J. M. Alvarez-Suarez, J. L. Quiles, B. Mezzetti, and M. Battino, "The strawberry: composition, nutritional quality, and impact on human health," Nutrition, vol. 28, no. 1, pp. 9-19, 2012.

[3] K. D. Vu, R. G. Hollingsworth, E. Leroux, S. Salmieri, and M. Lacroix, "Development of edible bioactive coating based on modified chitosan for increasing the shelf life of strawberries," Food Research International, vol. 44, no. 1, pp. 198-203, 2011.

[4] V. Kuchi and C. Sharavani, Fruit Physiology and Postharvest Management of Strawberry, Intechopen Books, London, UK, pp. 1-20, 2019.

[5] H. Li and T. Yu, "Effect of chitosan on incidence of brown rot, quality and physiological attributes of postharvest peach fruit," Journal of the Science of Food and Agriculture, vol. 81, no. 2, pp. 269-274, 2000.

[6] A. G. Pérez and C. Sanz, "Effect of high-oxygen and highcarbon-dioxide atmospheres on strawberry flavor and other quality traitsistry," Journal of Agricultural and Food Chemistry, vol. 49, no. 5, pp. 2370-2375, 2001.

[7] K. Pushpendra and S. Shruti, "Edible coating for fresh fruit: a review," International Journal of Current Microbiology and Applied Sciences, vol. 7, no. 5, pp. 2619-2626, 2018.

[8] B. A. Rahimi, T. H. Shankarappa, N. A. Sahel et al., "Effective edible coatings on control of microbial growth in strawberry fruits," Indian Journal of Ecology, vol. 46, no. 7, pp. 91-95, 2019.

[9] M. S. Tapia, M. A. Rojas-Graü, A. Carmona, F. J. Rodríguez, R. Soliva-Fortuny, and O. Martin-Belloso, "Use of alginateand gellan-based coatings for improving barrier, texture and nutritional properties of fresh-cut papaya," Food Hydrocolloids, vol. 22, no. 8, pp. 1493-1503, 2008.
[10] A. Allegra, P. Inglese, G. Sortino, L. Settanni, A. Todaro, and G. Liguori, "The influence of Opuntia ficus-indica mucilage edible coating on the quality of "Hayward" kiwifruit slices," Postharvest Biology and Technology, vol. 120, pp. 45-51, 2016.

[11] O. B. Sogvar, M. K. Saba, and A. Emamifar, "Aloe vera and ascorbic acid coatings maintain postharvest quality and reduce microbial load of strawberry fruit," Postharvest Biology and Technology, vol. 114, pp. 29-35, 2016.

[12] A. Allegra, G. Sortino, P. Inglese et al., "The effectiveness of Opuntia ficus-indica mucilage edible coating on postharvest maintenance of "Dottato" fig (Ficus carica L.) fruit," Food Packaging Shelf Life, vol. 12, pp. 135-141, 2017.

[13] V. Del-Valle, P. Hernández-Muñoz, A. Guarda et al., "Development of a cactus-mucilage edible coating (Opuntia ficusindica) and its application to extend strawberry (Fragaria ananassa) shelf-life," Food Chemistry, vol. 91, no. 4, pp. 751-756, 2005.

[14] L. V. Aquino, J. Rodriguez, L. L. Mendez et al., "Inhibicion del oscurecimiento con mucilago de nopal (Opuntia ficus-indica) en el secado se platano roatan," Informacion Tecnologica, vol. 20, no. 4, pp. 15-20, 2009.

[15] D. R. Olicón-Hernández, Á. Acosta-Sánchez, R. MonterrubioLópez, and G. Guerra-Sanchez, "Chitosan and Opuntia ficusindica mucilage as the base of a polymeric edible film for the protection of tomatoes against Rhizopus stolonifer," TIP Revista Especializada en Ciencias Químico-Biológicas,vol. 22, pp. 1-9, 2019.

[16] S. Riaz, M. T. Sultan, M. Sibt-e-Abass et al., "Extraction of polysaccharides from Opuntia cactus for its potential application in edible coating to improve the shelf life of citrus (Kinnow Mandarin) fruit," Journal of Microbiology, Biotechnology and Food Science, vol. 8, pp. 745-750, 2018.

[17] C. Sáenz, E. Sepúlveda, and B. Matsuhiro, “Opuntia spp. mucilage's: a functional component with industrial perspectives," Journal of Arid Environments, vol. 57, pp. 275-290, 2004.

[18] C. M. Messina, R. Arena, M. Morghese et al., "Seasonal characterization of nutritional and antioxidant properties of Opuntia ficus-indica [(L.) Mill.] mucilage," Food Hydrocolloids, vol. 111, p. 106398, 2021.

[19] M. I. Gil, J. R. Gorny, and A. A. Kader, "Responses of "Fuji" apple slices to ascorbic acid treatments and low-oxygen atmospheres," HortScience, vol. 33, pp. 305-309, 1998.

[20] J. Z. Acedo, D. A. C. Varron, I. C. Emnace et al., "Antimicrobial effects of ascorbic acid and calcium lactate in freshcut jackfruit (Artocarpus heterophyllus Lam.)," Acta Horticulturae, vol. 989, pp. 199-208, 2012.

[21] H. Qi, W. Hu, and A. Jiang, "Extending shelf-life of fresh-cut "fuji" apples with chitosan-coatings," Innovative Food Science and Emerging Technologies, vol. 12, pp. 62-66, 2011.

[22] K. S. Özdemir and V. Gökmen, "Effect of chitosan-ascorbic acid coatings on the refrigerated storage stability of fresh-cut apples," Coatings, vol. 9, no. 8, p. 503, 2019.

[23] A. Du Toit and M. De Wit, "A process for extracting mucilage from Opuntia ficus-indica and Aloe barbadensis," South Africa Patent No. PA153178/P, 2011.

[24] R. G. McGuire, "Reporting of objective color measurements," HortScience, vol. 27, pp. 1254-1255, 1992.

[25] G. Liguori, P. Inglese, O. Corona et al., "Effects of 1-methylcyclopropene on postharvest quality traits, antioxidant activity and ascorbic acid content of mature-ripe mango fruits," Fruits, vol. 72, no. 4, pp. 238-246, 2017.

[26] C. Ruiz-Capillas and A. Moral, "Use of semitrained panel members in the sensory evaluation of hake (Merluccius 
merluccius L.) analyzed statistically," Journal of Food Quality, vol. 26, pp. 181-195, 2003.

[27] G. Liguori, C. Gentile, G. Sortino et al., "Food quality, sensory attributes and nutraceutical value of fresh "osteen" mango fruit grown under mediterranean subtropical climate compared to imported fruit," Agriculture, vol. 10, no. 4, p. 103, 2020.

[28] E. Y. Gil-Giraldo, A. L. Duque-Cifuentes, and V. D. QuinteroCastano, "Obtaining minimally processed strawberry (Fragaria $x$ ananassa) products and their physicochemical, microbiological, and sensory characterization by using edible coatings," Revista DYNA, vol. 85, no. 207, pp. 183-191, 2018.

[29] T. K. Hazarika, Lalrinfeli, Lalthanmuani, J. Lalchhanmawia, and D. Mandal, "Alteration of quality attributes and shelf-life in strawberry (Fragaria $\times$ ananassa) fruits during storage as influenced by edible coatings," Indian Journal of Agricultural Science, vol. 89, pp. 28-34, 2019.

[30] A. d. J. Cenobio-Galindo, J. Ocampo-López, A. ReyesMunguía et al., "Influence of bioactive compounds incorporated in a nanoemulsion as coating on avocado fruits (Persea americana) during postharvest storage: antioxidant activity, physicochemical changes and structural evaluation," Antioxidants, vol. 8, p. 500, 2019.

[31] R. Das and G. Medhi, "Physio-chemical changes of pineapple fruits under certain postharvest treatments," South Indian Horticulture, vol. 44, pp. 5-7, 1996.

[32] M. Martinez-Ferrer, C. Harper, F. Perez-Muntoz et al., "Modified atmosphere packaging of minimally processed mango and pineapple fruits," Journal of Food Science, vol. 67, pp. 3365-3371, 2002.

[33] M. Suutarinen and K. Autio, "Improving the texture of frozen fruit: the case of berries," Texture in Food, Elsevier, Amsterdam, Netherlands, pp. 388-409, 2004.

[34] B. V. C. Mahajan, D. Kumar, and W. S. Dhillon, "Effect of different polymeric films on shelf-life and quality of pear fruits under supermarket conditions," Indian Journal of Horticulture, vol. 70, pp. 309-312, 2013.

[35] E. Sepúlveda, C. Sáenz, E. Aliaga et al., "Extraction and characterization of mucilage in Opuntia spp." Journal of Arid Environment, vol. 68, pp. 534-545, 2007.

[36] N. Patel, A. G. Naik, and S. S. Arbat, "Response of postharvest chemical treatments on shelf-life and quality of custard apple cv. Balanagar," Indian Journal of Horticulture, vol. 68, pp. 547-550, 2011.

[37] G. La Scalia, G. Aiello, A. Miceli et al., "Effect of vibration on the quality of strawberry fruits caused by simulated transport," Journal of Food Processing Engineering, vol. 39, pp. 140-156, 2016.

[38] A. L. Wszelaki and E. J. Mitcham, "Effect of combinations of hot water dips, biological control and controlled atmospheres for control of gray mold on harvested strawberries," Postharvest Biology and Technology, vol. 27, no. 3, pp. 255-264, 2003.

[39] M. Barth, T. R. Hankinson, H. Zhuang et al., "Microbiological spoilage of fruits and vegetables," in Compendium of the Microbiological Spoilage of Foods and Beverages, pp. 35-183, Springer, New York, NY, USA, 2009.

[40] G. Francis, C. Thomas, and D. O’Beirne, "The microbiological safety of minimally processed vegetables," International Journal of Food Science and Technology, vol. 34, pp. 1-22, 1999.

[41] J. Y. D’Aoust, "Current foodborne pathogens: salmonella," in Food Safety Handbook: Microbiological Challenges, M. Storrs, M.-C. Devoluy, and P. Cruveiller, Eds., pp. 128-141, BioMérieux Education, Marcy-l'Étoile, France, 2007. 